\title{
POLÍTICAS DE JUVENTUDES: HISTÓRIAS DE VIDA, EDUCAÇÃO E RESISTÊNCIA*
}

\author{
Mariana Lins de Oliveira ${ }^{1}$ \\ Luciana Rosa Marques ${ }^{2}$
}

\begin{abstract}
RESUMO: Este artigo tem como objetivo identificar experiências vivenciadas por jovens que, de alguma forma, caracterizam-se como de re(x)istência aos processos de normalização oriundos das políticas governamentais. Optamos, como estratégia de pesquisa, reconstruir as histórias de vida de dois jovens paraibanos. Para tanto, apoiamo-nos fundamentalmente em ferramentas foucaultianas, a fim de compreender melhor nosso objeto de pesquisa. Nossos achados apontam que os jovens têm construído tanto modos de vida que estão capturados pelos processos de normalização, como também demonstram, em certa medida, experiências de singularização ou de re(x)istência.
\end{abstract}

Palavras-chave: Políticas de juventudes. História de vida. Resistência.

\section{YOUTH POLICY: LIFE STORIES, EDUCATION AND RESISTANCE}

ABSTRACT: This article aims to identify experiences lived by young people who, somehow, characterized as re(x)istence to standardization processes from government policies. This research reconstructs the life stories from two young boys from the Brazilian state, Paraíba. Therefore, we are fundamentally supported by Foucault's theory to better understand our research object. We find young people who have built ways of life that are captured by the standardization process, but also demonstrate singular experiences or re(x)istence.

Keywords: Youths policies. Life history. Resistance.

\footnotetext{
*Artigo resultante de pesquisa de doutoramento desenvolvida no Programa de Pós-Graduação em Educação da UFPE na Linha de Pesquisa Política Educacional, Planejamento e Gestão da Educação durante os anos de 2011 e 2015.

${ }^{1}$ Universidade Federal da Paraíba (UFPB), Departamento de Psicopedagogia - João Pessoa (PB), Brasil.

E-mail: mariloliveiras@gmail.com

${ }^{2}$ Universidade Federal de Pernambuco (UFPE), Departamento de Administração Escolar e Planejamento Educacional (DAEPE)/Núcleo de Política Educacional, Planejamento e Gestão da Educação do Programa de Pós-Graduação em Educaçáo - Recife (PE), Brasil. E-mail: lmarques66@gmail.com

DOI: 10.1590/ES0101-73302016166171
} 


\title{
POLITIQUES DE LA JeUNESSE: HISTOIRES DE VIE, EDUCATION ET RÉSISTANCE
}

\begin{abstract}
RÉSUMÉ: Le présent article a l'objectif d'identifier les expériences vécues par des jeunes, qui, dans une certaine mesure, se caractérisent par une ré(ex)sistance aux processus de normalisation issus des politiques gouvernementales. Nous avons adopté comme stratégie de recherche la reconstitution des parcours de vie de deux jeunes de l'état de Paraïba, au Brésil. Les outils et travaux de Foucault ont constitué une base conceptuelle pour mieux appréhender ce sujet de recherche. Nos résultats révèlent que les jeunes, en même temps qui ont développé des modes de vie empreints de processus de normalisation, aussi révèlent des expériences de singularisation et ré(ex)sistance.
\end{abstract}

Mots-clés: Jeunesses politiques. Parcours de vie. Résistance.

\section{De onde partimos...}

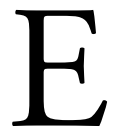

ste texto é um recorte da nossa pesquisa de doutorado, desenvolvida no Programa de Pós-graduação em Educação da Universidade Federal de Pernambuco (UFPE), na linha de pesquisa Política Educacional, Planejamento e Gestão da Educação, entre os anos de 2011 e 2015. O estudo foi realizado junto a cinco jovens moradores das periferias do estado da Paraíba ${ }^{1}$. Realizamos uma investigação sobre os modos como esses sujeitos criam estratégias de re(x)istência, expressas em maneiras outras de vivenciar a juventude. Em outras palavras, o estudo parte de um enfoque naquilo que os jovens experienciam em termos de sua condição juvenil, do que constroem e/ou desconstroem a partir de suas subjetividades, em relação ao que circula a respeito dessa condição nos discursos próprios das políticas a eles destinadas. Optamos, como estratégia de pesquisa, por reconstruir as histórias de vida de dois jovens; um morador da comunidade de São Rafael, em João Pessoa, e o outro do município de Zabelê, pequena cidade do Cariri paraibano.

Encontramos os jovens para ouvir suas histórias de vida, tendo como objetivo compreender como eles têm construído modos de vida que extrapolam as normatividades, não se contrapondo necessariamente à própria política, mas indo além, excedendo-se nos discursos vigentes, presentes na sociedade sobre as juventudes pobres.

Desde meados do século passado, a questão da juventude tem sido alvo de preocupaçóes políticas, e têm sido muitos os investimentos internacionais no sentido de atender às demandas dos jovens. Nesse sentido, as açóes têm se voltado tanto para o cuidado e proteção, quanto para a busca de intervenção nos comportamentos considerados transgressores.

Conforme registra a literatura sobre o tema, essa questão surgiu, de um lado, em virtude da crise que perpassa as sociedades e as soluçóes que visam a 
contorná-las (o que tem se expressado em profundas mudanças no mundo do trabalho, reconfigurando a pobreza e aumentando os graus da denominada "marginalidade"); de outro, pela associação direta entre as juventudes e a violência, o que justificaria as intervençóes de controle de suas condutas.

Diante desse contexto, o governo brasileiro, nas suas três instâncias, tem elaborado e executado políticas específicas para esse grupo populacional. Trata-se de políticas que se orientam por concepçóes construídas no embate das relaçôes entre determinados grupos da sociedade civil e do Estado. Desde final dos anos 1990 e início dos anos 2000, vimos os discursos do protagonismo político e do reconhecimento dos direitos específicos das juventudes serem incorporados às metas dos programas governamentais. Paralelamente a esse discurso, e de forma contraditória, as políticas funcionam como dispositivos reguladores e normalizadores das condutas dos jovens.

Como toda política pública é orientada por um referencial normativo, parece-nos que os atuais programas governamentais são orientados pela ideia da juventude como um problema ou uma ameaça à ordem social. De acordo com diagnósticos apresentados pelos formuladores das políticas sobre os jovens pobres, eles têm sido classificados como estando em "situação de risco" e, por isso, demandam açóes interventivas do Estado. Contudo, o modo como esses mesmos jovens veem a sua própria condição não corresponde necessariamente aos indicadores das políticas públicas (OLIVEIRA, 2015).

Nesse sentido, com base em estudos anteriores, como os de Oliveira (2011), Tenório Cavalcanti (2011) e Freitas (2009), e nos apoiando em ferramentas foucaultianas, consideramos que as políticas de juventude no Brasil funcionam como estratégias de governamento da vida dos jovens, o que Foucault denominaria de estratégia biopolítica. O "governo da vida" significa o controle dos comportamentos e das subjetividades dos indivíduos. Foucault esclarece-nos que, ao falar de governo, ele não está se referindo à instituição "governo", mas à atividade que consiste em reger a conduta dos homens em um quadro e com instrumentos estatais (FOUCAULT, 2008, p. 432). Com um funcionamento de caráter político, a biopolítica constitui cortes populacionais que se tornam alvo de ação governamental, como é o caso das juventudes pobres. Ou seja, o próprio discurso que adjetiva os jovens pobres como estando em "situaçáo de risco" funciona como dispositivo de controle sobre suas condutas. Dito de outra forma, é um discurso que defende a reinserção das juventudes pobres dentro dos moldes de comportamento socialmente aceitos: condutas consideradas "normais".

É importante frisar que não estamos aqui nos posicionando contra ou a favor dessas políticas, mas simplesmente buscando, a partir das narrativas dos jovens, apreender os pontos de re(x)istência construídos e vivenciados por eles. As narrativas de vida são formas de expressão das experiências humanas. Tudo que vivenciamos, nossos sentimentos, impressóes e memórias da vida cotidiana, de maneira geral, podem ser comunicadas por meio de narrativas. Independentemen- 
te de níveis de formação e educação, os grupos sociais, comunidades e subculturas "contam histórias com palavras e sentidos que são específicos à sua experiência e ao seu modo de vida" (JOVCHELOVITCH; BAUER, 2010, p. 91).

As políticas de juventude têm se configurado como programas governamentais de prevenção e de segurança dos jovens pobres. Essas políticas operam por meio de categorias que funcionam como dispositivos de normalização e de controle dos comportamentos desse grupo populacional. Porém, como já mencionamos anteriormente, nossa pesquisa buscou identificar experiências vivenciadas por jovens que, de alguma forma, caracterizam-se como de re(x)istência aos processos de normalização oriundos das políticas governamentais. Nesse sentido, podemos afirmar que o exercício da biopolítica não só reprime e regulamenta as açóes, mas também faz surgir novas realidades, a partir das reaçóes dos sujeitos implicados nessas relaçóes de poder.

\section{Políticas de juventude e o governo da vida}

A juventude, como todo fenômeno social, é uma construção humana que envolve distintas dimensóes. É por isso que Bourdieu vai dizer que "a juventude é apenas uma palavra”, significando que não pode ser tomada em abstrato. Por outra parte, a juventude se tornou uma questão socialmente problematizada. A concepção de juventude diretamente articulada à anomia e à desordem ou disfunção social originou-se nos estudos desenvolvidos pela Escola de Chicago no início do século XX, quando foram pesquisados os conflitos entre gangues, bandos e organizações clandestinas, compostos por jovens imigrantes, nos grandes centros urbanos dos Estados Unidos. Nessa ótica, as rebeldias juvenis são explicadas como disfunçóes, e a delinquência é considerada o tipo mais característico desse comportamento desviante. Os problemas como a delinquência, o comportamento de risco e o forte uso de drogas passam a suscitar a intervenção por parte da sociedade a fim de contorná-los (GROPPO, 2010; ZALUAR, 1997).

De fato, no imaginário das sociedades existe uma forte tendência em relacionar os índices de violência ao comportamento dos jovens de periferia, demonstrando, assim, desconhecimento sobre as situaçóes que originam esses comportamentos - entre elas, o fato de que são esses próprios jovens as maiores vítimas. Em tal contexto, o tratamento reservado às questóes juvenis pouco considera as dimensóes econômica, política, social e cultural nelas implicadas. Conforme Sposito (2007), o modo de tratamento que privilegia as relaçóes entre a juventude e a violência é fortemente influenciado pela mídia. Ou seja, como a mídia tem privilegiado fortemente notícias sobre situaçóes de violência em que jovens e adolescentes se encontram envolvidos, ela influencia a sociedade no sentido de cristalizar uma percepção negativa sobre eles.

A existência de consensos preliminares em torno da relevância da temática da juventude, nos anos 1990, não exclui a pluralidade de orientaçóes e 
pressupostos que têm norteado os projetos e programas voltados para os jovens brasileiros. Assim, no próprio interior dos aparelhos de Estado, as políticas públicas para a juventude apresentam orientaçóes diversas, podendo optar por diferentes prioridades, em face de várias demandas. Tais políticas podem se aproximar seja de modelos participativos e democráticos, seja de modelos que, no Brasil, foram designados, tradicionalmente, como de cidadania tutelada (SPOSITO; CARRANO, 2003, p. 7), cujas orientaçóes têm reflexo direto na forma como tais políticas equacionam suas relaçóes com os segmentos juvenis.

Assim sendo, pode-se distinguir dois movimentos em relação aos jovens brasileiros. De um lado, a juventude é abordada como uma espécie de reservatório de energias "utópicas", possuidora de grandes potencialidades para o desenvolvimento socioeconômico do país. De outro lado, o foco é posto no estado de precariedade em que vivem os jovens, a exemplo do crescimento do desemprego juvenil - problema que pode ser contornado pelas famílias privilegiadas por meio do prolongamento dos estudos, oportunidade indisponível aos jovens oriundos de famílias menos favorecidas.

Mesmo tomando o marco da década de 1990 como um diferencial na discussão das políticas públicas de juventude, é possível definir que a representação simbólica do termo juventude e suas contradiçóes continuam vinculadas à ideia de um "problema social” e, por isso, seria necessário governar suas condutas.

\section{Sociedade de normalização, re(x)istência e as possibilidades de construir outros modos de vida}

De acordo com Foucault, o poder, tal como se apresenta na sociedade moderna, é progressivamente exercido em um campo em que predomina a norma em vez da lei. Ao mesmo tempo, ele entende que, ao falarmos da norma, não se trata apenas de repressão a uma dada natureza ou às individualidades dos sujeitos e, sim, de um dispositivo que forma essas individualidades. Ou seja, a norma funciona como um dispositivo formador de indivíduos.

Ele nos chama a atenção para a importância de distinguir a norma da lei. A norma diferencia os indivíduos baseada em uma média, em um modelo ótimo de comportamento que se deve buscar alcançar. A norma busca a homogeneização, embora reconheça o anormal, o diferente. A norma é quantificadora e hierarquizadora dos comportamentos dos indivíduos. A lei, contudo, funciona no sentido da correção, da condenação, do permitido e do proibido (CASTRO, 2009). Dessa perspectiva, vivemos em uma sociedade que funciona cada vez mais sob a lógica da norma. Ou seja, a própria lei funciona cada vez mais como uma norma e como um dispositivo de normalização.

A sociedade de normalização nasce juntamente com a formação do Estado governamentalizado. $\mathrm{O}$ dispositivo de normalização será denominado por Foucault de "governamentalização". Isto é, 
um processo complexo de objetivação e subjetivação de normas sociais, a partir do qual os poderes públicos engendram formas de governo que pretendem qualificar um contingente populacional apreendido ora como "incluídos" ora como "excluídos" do sistema de direitos (FREITAS, 2009, p. 8).

O funcionamento da sociedade de normalização requer o uso do biopoder, tornando-o indispensável. A modernidade faz emergir duas formas distintas de funcionamento do poder: o poder disciplinar, que age sobre os corpos, e o biopoder que, diferentemente da disciplina, age sobre populaçóes. $O$ funcionamento do biopoder desenvolve sua ação e localização sobre a relação de poder, que "se situa e exerce no nível da vida, da espécie, da raça e dos fenômenos maciços de uma população" (FOUCAULT, 2008, p. 129).

A biopolítica funciona como uma estratégia de governo da vida e opera se utilizando desses dois dispositivos: a disciplina e o biopoder. Esses são modos diferentes de exercício do poder, mas que não são excludentes; ao contrário, complementam-se. Veiga-Neto e Lopes (2007) afirmam que o governamento é a manifestação "visível", "material" do poder.

Para Lazzarato (2008, p. 3, grifo nosso),

governar é exercer uma ação sobre açóes possíveis. Governar consiste em agir sobre sujeitos que devem ser considerados livres. Foucault já tinha falado de governo para explicar os dispositivos de regulaçáo e de controle dos doentes, dos pobres, dos delinquentes ou dos loucos.

O surgimento do Estado moderno traz, com ele, os elementos que caracterizam a governamentalização. Ao classificarmos um grupo populacional como sendo de juventude, acionamos uma gama de saberes que aparecem acoplados a esses grupos. Esses saberes, que compóem o processo classificatório de diferentes segmentos da população, funcionam como uma estratégia de melhor governamento.

Mesmo que as atuais políticas de juventude estejam operando na lógica da biopolítica, atuando como reguladoras da populaçáo jovem, esses mesmos jovens têm conseguido (re)agir de alguma forma a essa regulação, considerando que todo exercício do poder pressupóe uma margem de liberdade. Como afirma Freitas (2009, p. 15),

nesse ponto a análise de Foucault também é incisiva, toda forma de exercício do poder supóe uma margem de liberdade. Assim, se é verdade que a biopolítica aponta para o processo de regulamentação da população jovem pela cifra da segurança, por outro lado, a noçáo torna evidente que as subjetividades, os modos como os jovens se constituem na relação consigo mesmos e com os outros, constituem, na contemporaneidade, o lugar de emergência de contrapoderes. 
Nesse sentido, podemos afirmar que o exercício da biopolítica não só reprime e regulamenta as açōes, mas também faz surgir novas realidades, a partir das reaçóes dos sujeitos implicados nas relaçóes de poder. Nessa mesma direçáo, referindo-se à dimensão criadora do poder, Pelbart (2003, p. 26) afirma que:

[...] contra o biopoder, que produz e reproduz não apenas mercadorias, mas também subjetividades e consciências, Negri e Hardt detectam o alastramento daquilo que denominaram como biopotência plural da Multidáo, manifesta em laços de cooperação social, de união afetiva e política, de subversão e escape, de protesto e criação, de inteligência e desejo de liberdade nelas existentes e assumir a crítica permanente entre todos os fenômenos de dominação.

A atitude crítica em Foucault está relacionada a uma crise, a uma desconfiança ou a uma resistência aos processos de governamento dos sujeitos. Branco (2001) afirma que Foucault defende as resistências ao poder como aquelas que almejam a liberdade.

Entendendo a resistência como uma força que é capaz de provocar um movimento de não enquadramento e de não adaptação a determinados formatos - e considerando o seu poder de gerar novas realidades -, podemos identificar o seu caráter político. Estamos tomando o "político" baseado nas ideias de Ortega (2009, p. 23): tendo como referência o pensamento de Arendt, Derrida e Foucault, o autor defende uma concepção de política e de espaço público como "criação e experimentação". Há um esforço em Ortega de investigar os modos como são recriados os espaços de experimentação da vida, por meio da autoconstituiçấo dos sujeitos (processo denominado por Arendt, Foucault e outros como "estilo"). Tendo como parâmetro o pensamento desses teóricos, sentimo-nos provocados a pensar e a realizar estudos sobre as possibilidades de apreendermos modos de convivência que afrontem as formas institucionalizadas de exercício do político.

Para fins deste artigo, compreendemos como re(x)istência a possibilidade de criação de versóes próprias de subjetividades, ou seja, modos de ser que procuram escapar, de certo modo, dos processos de assujeitamento. A resistência é algo que faz parte das relaçóes humanas e que se configura como um movimento de reelaboração de si mesmo e de formas outras de vida, diferentes das predeterminaçóes das sociedades de controle. Persistência em dar vida à sua própria existência. Essa resistência se constrói a partir das experiências de vida, da família, de grupos de referência; e se volta à construção de formas plurais de ser.

É nesse sentido que apresentaremos as narrativas de vida de jovens que expressam, de algum modo, pistas de como eles têm construído formas outras de existir e estar no mundo. 


\section{Os jovens e suas histórias de vida}

Como já mencionamos anteriormente, optamos por trabalhar com as histórias e narrativas de jovens, a fim de identificarmos possíveis (re)açóes de resistência aos padróes normativos estabelecidos sobre suas condiçóes. $\mathrm{O}$ estudo de histórias de vida tem conquistado um grande espaço e importância nas últimas décadas. No campo educacional, as histórias de vida têm sido amplamente utilizadas para estudos sobre experiências formativas.

Para os pesquisadores interessados nos modos como os sujeitos experienciam o mundo, como constroem e (re)constroem suas histórias pessoais e sociais, as teorias narrativas podem ser eleitas como um excelente procedimento de pesquisa. As teorias biográficas devem sempre ter um compromisso com o nascimento de um texto, de uma narrativa ou de uma história.

Pineau (2008/2009) nos alerta para questóes epistemológicas de fundo, que acompanham as contradições e contribuições do método biográfico. Falar de histórias de vida significa abordar, inevitavelmente, questôes sobre o que é a "vida", sobre as diferenças entre vida privada e pública, a relação entre passado e futuro, e sobre as relaçóes entre nossa vida e a dos outros. Ou seja, quando estamos tratando de narrativas de vida, essas temáticas aparecerão, de algum modo, tanto para o pesquisador como para o narrador.

De acordo com Ricoeur (2010, p. 203), o grande paradoxo que enfrentamos quando tratamos de histórias de vida é que "as histórias se narram, a vida é vivida". Esse paradoxo aparenta criar um fosso entre a ficção e a vida e, para superá-lo, torna-se necessário fazer uma revisão aprofundada dos dois termos: ficção e vida. Para ele,

O processo de composição, de configuração, não se finaliza no texto, mas no leitor, e sob essa condiçáo torna possível a reconfiguração da vida pela narrativa. [...] O sentido ou a significação de uma narrativa brota na interseçáo do mundo do texto e do mundo do leitor. $\mathrm{O}$ ato de ler torna-se assim o momento crucial de toda análise. Sobre ele se apoia a capacidade da narrativa de transfigurar a experiência do leitor (RICOEUR, 2010, p. 203, grifo nosso).

$\mathrm{O}$ argumento seminal radica-se na compreensão de que um texto não se esgota em si mesmo, pois pode nos conduzir à projeçáo de um novo universo, diferente do que vivemos. Apropriar-se da leitura de uma narrativa conduz ao desdobramento de uma realidade que contém açôes, personagens e acontecimentos das histórias que nos foram narradas.

As narrativas são formas de expressão das experiências humanas. Tudo que vivenciamos, nossos sentimentos, impressóes e memórias da vida cotidiana, de maneira geral, podem ser comunicadas por meio de narrativas. Independentemente de 
níveis de formação e educação, os diversos grupos sociais, comunidades e subculturas "contam histórias com palavras e sentidos que são específicos à sua experiência e ao seu modo de vida" (JOVCHELOVITCH; BAUER, 2010, p. 91).

A escuta dos jovens nos permitiu uma aproximação das reelaborações que eles criam sobre as suas próprias experiências de vida. Essas construçôes estão conectadas a um momento social e histórico específico, que possibilita aos jovens falar de certas coisas e de certos temas, com um sentido ou outro. As narrativas consistem em uma possibilidade de expressão da forma como eles próprios veem e sentem o mundo.

Conseguimos realizar entrevistas junto a cinco joven $s^{2}$ moradores das periferias do estado da Paraíba. Eles se dispuseram a nos narrar suas histórias de vida. No mergulho nessas histórias, percebemos que algumas estão conectadas de maneira direta. Os critérios para escolha dos jovens a serem entrevistados foram os seguintes: morar em comunidades periféricas; ter algum envolvimento de trabalho com as juventudes ou ter participado de algum programa governamental voltado para jovens pobres; estar disposto a participar da pesquisa e dividir sua história de vida conosco.

Realizamos entrevistas em profundidade na cidade de João Pessoa (PB). Chegamos até os jovens por meio de educadores de ONGs locais, já que tínhamos esses contatos. O primeiro contato foi por telefone e por e-mail e, posteriormente, marcamos o dia e o horário das nossas longas conversas. Cada entrevista teve suas particularidades, as quais foram devidamente registradas no nosso diário de bordo.

Durante as entrevistas, procuramos assumir certos cuidados. Inicialmente, ainda nos primeiros contatos, apresentamo-nos e contamos um pouco da trajetória da pesquisa e dos nossos interesses pelas juventudes. Em seguida, perguntamos se o jovem tinha interesse em participar do estudo. As histórias que trabalharemos neste artigo são as de Hélder e Márcia. Procuraremos (re)construir suas histórias, lembrando que, em função dos limites de espaço deste texto, não poderemos nos prolongar nas narrativas ${ }^{3}$.

\section{Márcia: "Hoje em dia, eu sou pedagoga pelo fazer na comunidade"}

Márcia mora na comunidade de São Rafael ${ }^{4}$, em João Pessoa. Na São Rafael, existe um Centro Popular de Cultura e Comunicação (CPCC), onde são desenvolvidas várias açóes de formação cultural, profissional e de mobilização da comunidade. Por meio desse centro, vários jovens da comunidade fazem funcionar uma rádio, uma padaria e um banco comunitários. Márcia disse ter participado de toda a elaboração dessas açóes, inclusive atuando na formação de outros jovens que na atualidade são protagonistas dessas atividades.

Márcia é pedagoga e afirma que se fez educadora durante sua trajetória de atuaçáo na comunidade. Ela falou de forma exaustiva sobre sua família, com destaque para a relação que mantém com seus pais; contou sua trajetória escolar 
com riqueza de detalhes - ela foi reprovada mais de uma vez e me contou esses episódios com certo tom de ironia e de crítica ao funcionamento da escola; disse também que sempre gostou de praticar esportes e que, na escola, jogava todas as modalidades possíveis. Quando adolescente, ela participou, durante vários anos, da organizaçáo dos jogos escolares. A jovem, que sempre estudou em escola pública, era bastante participativa nas atividades extraclasses; inclusive, ajudou a criar o grêmio estudantil da escola em que fez ensino médio. Ela disse que nunca gostou de estudar, mas que se dedicava minimamente para não desistir. "Eu sou preguiçosa, sempre fui. Mas me dedicava para tirar notas boas”.

Após o ensino médio, Márcia cursou o magistério e, segundo ela, o fez em um ano, pois já havia "terminado os estudos”. Durante o estágio do magistério, ela vivenciou sua primeira experiência como alfabetizadora e, paralelamente, envolveu-se como participante de projetos oferecidos por ONGs, na comunidade de São Rafael. "Sempre gostei de trabalhar com jovens e adultos porque, eu falo comigo mesma, é de jovem para jovem”. Depois do magistério, ela cursou Pedagogia na Universidade Federal da Paraíba (UFPB). Márcia é a única de sua família a ter tido oportunidade de ingressar no ensino superior.

Márcia afirmou que todos a conhecem e que ela também conhece bem a comunidade de São Rafael. "Se perguntar quem sou aqui vão dizer: 'Márcia da rádio, da universidade, da padaria”. Há mais de 10 anos, ela desenvolve açóes educativas e de cuidado junto à comunidade. Ela disse que gosta de estar envolvida em trabalhos coletivos, de estar junto de pessoas e fazer parte de grupos. "Eu gosto de participar. Tenho facilidade para me relacionar com grupos. Eu sou muito na minha, mas eu gosto de tá [sic] participando, de ajudar, de fazer, de contribuir”. Márcia se considera uma referência para outros jovens na comunidade. Além disso, afirmou que não pretende sair da São Rafael, pois gosta do trabalho que lá realiza como alfabetizadora e que valoriza as relaçóes afetivas que estabeleceu nesse lugar.

\section{Helder: "Na associação, eu aprendi a sonhar"}

Helder nasceu e cresceu na cidade de Zabelế${ }^{5}$. Ele é o único da sua família que teve oportunidade de ingressar na universidade. Seus pais eram comerciantes e não tiveram oportunidade de estudar. Ele fez todo o ensino básico em Zabelê, em escolas públicas. "Eu sempre fui muito tranquilo na escola. Eu, eu sou muito ansioso... se passa uma atividade eu quero fazer na hora; eu nunca tive problema”. Durante sua trajetória escolar, participava do grupo de teatro da igreja e do grupo folclórico da escola. Ele nos contou desse grupo com bastante entusiasmo: "Era muito bom; a gente gostava muito porque a gente relaxava, na verdade. Todo mundo fazia questão de ir”. Helder afirmou que o grupo folclórico lhe proporcionou "aprendizagens diferentes" do que era ensinado em sala de aula. Segundo o jovem, o grupo foi um espaço de "mudança de consciência". 
Helder cursa economia na UFPB e participa de projetos na área de economia solidária. Juntamente com outros 13 jovens, faz parte de um coletivo juvenil chamado: "Atissar". Segundo ele, "o nome é escrito com dois 's' de propósito, com intenção de provocar indagaçôes". Curiosamente, ele nos contou que os membros do coletivo "Atissar" passam todas as datas comemorativas do ano, como Natal, Ano Novo etc., juntos. "O coletivo criou formas de conviver tendo como princípio o cuidado e a formaçáo dos seus membros". Esse coletivo tem como objetivo desenvolver projetos culturais em Zabelê, bem como despertar sonhos nos jovens da cidade. Helder disse que gostaria de ver a população de Zabelê aprendendo a sonhar, como ele pôde aprender.

Ouvimos histórias longas, que retratam infâncias, relações com famílias, processos de escolarização, experiências "inusitadas" de formação, construçôes e ligaçôes com territórios. Tratam da vida de jovens, de re(x)istências, do como se fazer e se (re)fazer jovem nas comunidades periféricas. Sabemos que, no âmbito deste artigo, é quase impossível trazer todas as nuances das histórias. O que tentamos fazer foi apresentar, minimante, as histórias de vida de Márcia e Hélder.

As narrativas que ouvimos são carregadas de emoçóes, de lembranças e sonhos. Ao (re)construirmos as falas dos jovens, chamou-nos atenção o forte compromisso que todos demonstraram firmar junto à sua comunidade. Paralelamente a esse sentimento de pertença, observamos uma motivação: querer retribuir os experimentos que puderam viver nos coletivos, ONGs, associaçóes e outros. As histórias nos falam de certo engajamento com a formação de outros jovens, de re(x)istências que se constroem junto ao outro, de forma solidária e cooperativa.

\section{Os entrelaços das narrativas: uma leitura foucaultiana da re(x)istência à normatização}

Nas narrativas analisadas, identificamos relatos de histórias de vida que podem ser tomadas como fuga aos processos de assujeitamento. Nesse sentido, há jovens que, em certa medida, escaparam aos ritos e práticas da instituição escolar e de outros agenciamentos hegemônicos, construindo modalidades paralelas de formação.

As histórias de vida contêm muitas indicaçóes de que os jovens desenvolvem estratégias que buscam "fugir" aos processos de normalizaçâo. Essas fugas podem ser entendidas como resistência, ao se considerar que elas são um vetor de desorganização da norma. Todavia, são experiências que não devem ser entendidas somente como provocadoras de grandes rupturas e sim como momentos de resistência instáveis e transitórios (FOUCAULT, 1997).

Nessa direção, nas narrativas encontramos experiências de escapamento ao funcionamento da instituição escolar. Márcia expressou uma relação conflituosa com a instituição escolar, afirmou que nunca gostou de estudar: "Eu sou 
preguiçosa, sempre fui”. Entretanto, falou que se esforçava para permanecer na escola: "Mas me dedicava pra tirar notas boas".

Ainda que afirme o tempo todo que não gosta de estudar, ao permanecer no ambiente escolar ela denota vivenciar uma relação de ambiguidade com a instituição. Em determinadas situaçóes, ressaltou pontos positivos da escola: a possibilidade do brincar e jogar, a relação com os professores e demais funcionários, e principalmente, uma atração por atividades extraclasses. "Só lembro de brincar, sabe?! De brincar” (Márcia).

Assim como outras instituiçóes disciplinares, a escola deve, por meio do ensino e do exercício contínuo, diminuir os comportamentos desviantes. Trata-se de uma fabricação que quase sempre se realiza de maneira sutil, de modo que as açóes desenvolvidas para tanto podem nem ser percebidas como instrumento de individuação, assujeitamento e normalização (FOUCAULT, 2012). Entretanto, as narrativas dos jovens indicam certa recusa ao enquadramento que a escola procura fazer.

Sabemos que há outros espaços formativos vivenciados no interior da escola, além da sala de aula. Esses espaços foram explorados pelos jovens, em suas narrativas. Helder, por exemplo, sempre fez parte do grupo folclórico da escola. E diz que foi nesse espaço que pôde entrar em contato com "novas realidades". Foi no grupo que ele teve contato com músicas que chama de "raiz", referindo-se aos gêneros musicais regionais; músicas que, até então, ele não tivera possibilidade de conhecer. "A gente viajava muito pra outros interiores, fazendo apresentaçôes em escolas, em várias festividades dos municípios [...] na verdade é o seguinte... Há também resistências iniciais do município com tudo o que surge de novo, tem resistência" (Helder).

Como podemos observar nas narrativas de Márcia, ela esteve bastante envolvida com os jogos escolares e com o grêmio estudantil. "Lá na escola, a gente se envolveu com o grêmio, jogos internos, né?! Jogos escolares. A gente... Acho que eu participei de uns cinco. Do $5^{\circ}$ até o $3^{\circ}$ ano Médio" (Márcia). Nessas vivências, aprendeu a liderar grupos, aprendeu sobre o significado do "espírito de coletividade" e de participação. Essas experiências podem ser consideradas de suma importância para aprendizagens outras que não são abordadas em sala de aula. São aprendizagens que não estão previstas e calculadas em um determinado tempo e com objetivos preestabelecidos. Elas se dão nas relações entre os sujeitos onde ocorre o processo formativo. São os seres envolvidos nelas que guiam esse processo. Nesses casos, o educador é o outro com quem eu convivo. O educador é aquele com quem interagimos ou nos integramos (GOHN, 2006).

Notamos que os jovens resistem, em parte, aos rígidos processos de escolarização. Contudo, a escola não deixa de exercer seu papel de instituição disciplinadora e de controle dos comportamentos. Ou seja, há um movimento que é elástico, ele perpassa pelo governo de condutas, mas provoca, ao mesmo tempo, atitudes reativas e criativas. 
A escola pode proporcionar vivências formativas de práticas associativas e esse movimento permite alguma fuga dos processos de governamento. É nessa perspectiva que Pelbart (2003) se refere à biopotência expressa em laços de cooperação social, afetivos e políticos, de escapamento da ordem, de protesto, de criação e desejo de liberdade.

As políticas de juventude das últimas décadas, desde o governo Lula, preveem a inserçáo dos jovens pobres no ensino superior. O Estatuto da Juventude, no artigo 13, prevê que "as escolas e as universidades deverão formular e implantar medidas de democratização do acesso e permanência, inclusive programas de assistência estudantil, ação afirmativa e inclusão social para os jovens estudantes" (BRASIL, 2013). Nesse mesmo sentido, o Ministério da Educação instituiu que $25 \%$ das vagas das universidades e institutos federais devem ser reservadas a alunos que cursaram o ensino médio em escolas públicas ${ }^{6}$. Essas medidas têm facilitado o ingresso dos jovens nas instituiçóes de ensino superior; contudo, isso não garante que esses mesmos jovens sintam-se inseridos. Se, por um lado, a política de cotas tem garantido o acesso à graduação, por outro, depois de estarem cursando, os jovens ainda são vistos como os "estranhos", fora de lugar. Levam uma marca de serem os "jovens cotistas", pobres, oriundos de escolas públicas e de alguma forma menos "potentes"

Os jovens entrevistados se referiram a situações de suas histórias de vida que refletem justamente o modo como os grupos sociais os discriminam e como eles resistem, em parte, a essa discriminação. Tratando de suas vivências, os jovens mencionaram experiências negativas de discriminação por parte de colegas e de educadores, durante o seu processo de formação.

Márcia, por exemplo, demonstra satisfação por ter tido oportunidade de ingressar na universidade. Contudo, afirma que lá viveu o sentimento de ser vista como alguém diferente, estranha. Ela sentia que os professores não acreditavam que ela pudesse estar naquele lugar e acompanhar o curso, por ser moradora da periferia.

A Universidade ela é muito elitizada, né?! E eu vim desde o primeiro dia de sala de aula até o último dia de sala de aula dizendo que as pessoas de periferia também podiam ir pra Universidade e tem um potencial. Eu defendia muito, eu sempre fui muito brigona dentro da Universidade. [...] (Márcia).

As narrativas explicitam a vivência de situaçóes discriminatórias, vinculadas ao pertencimento a um território estigmatizado. Os sujeitos que habitam o bairro, muitas vezes, incorporam os discursos negativistas propagados socialmente sobre comunidades periféricas. Como podemos verificar na fala de Helder: "por isso que eu disse no início, que considero Zabelê como um todo uma comunidade pobre. É pobre de pensamento".

Hegemonicamente, difunde-se uma ideia de que jovens de periferia carregam, naturalmente, certa impotência. Eles são, frequentemente, correlacionados 
a açóes de violência, na maioria das vezes como um agente dessas açóes. No limite, são tidos, constantemente, como uma ameaça à ordem social. As situações discriminatórias, no entanto, não os levaram a se posicionar em uma condição de inferioridade, que viesse a cercear suas vivências nas instituiçóes formativas. Ao contrário, os jovens insistem em demarcar seu espaço nas instituiçóes, mesmo que permaneçam portando determinados estigmas.

$\mathrm{Na}$ mesma direção, as políticas de inclusão educacional de jovens apresentam uma incorporação do discurso que é difundido na sociedade sobre os jovens moradores das periferias. Assim como toda política pública, suas ações são orientadas por referenciais normativos (AZEVEDO, 2003); nesse caso, por uma ideia sobre o que representa um jovem morador das periferias. Esse referencial é que vai orientar a elaboração e materialização dos programas governamentais e essa materialização, por sua vez, ocorre nas diferentes instituiçóes educacionais.

Nesse sentido, mesmo que os programas governamentais assumam um posicionamento que defende a "inclusão dos jovens", essa é provocadora de situaçóes excludentes. As políticas exercem açóes de “inclusão para excluir", tendo como dispositivo de funcionamento a norma. As políticas de inclusão são pautadas no direito à igualdade e se utilizam de processos classificatórios, de aproximação e comparação, para garantir o ordenamento dos grupos populacionais. Dessa forma, as entidades educacionais são consideradas inclusivas quando garantem acesso e permanência a todos. Isso não quer dizer que, durante os processos classificatórios, não haja quem permaneça excluído. Assim, o mesmo lugar que pode ser considerado de inclusão, pode ser tido também como excludente (VEIGA-NETO; LOPES, 2007, p. 959). Entretanto, há jovens que criam estratégias para escapar das situaçóes excludentes.

\section{Vivenciando outros espaços formativos}

No mundo da vida dos jovens, são recorrentes os processos formativos que acontecem em práticas associativas situadas nas comunidades, possibilitando a formação de redes sociais.

As redes sociais podem se constituir em espaços nos quais as dimensões da liberdade e da igualdade se vinculam pelo princípio da solidariedade (FREITAS, 2005, p. 220). Para o autor, as redes sociais tecidas nessa perspectiva podem dar um novo sentido à democracia social, que "deixa de ser vista como uma simples redistribuição dos bens, no sentido unívoco das políticas públicas emanadas do sistema estatal. Ela passa a ser abordada do registro do intereconhecimento e do pertencimento coletivo".

Os jovens entrevistados disseram ter vivenciado experiências formativas fora da sala de aula e em outros espaços sociais de aprendizagem (ONGs, projetos sociais, coletivos juvenis, associaçóes culturais e de moradores, e açóes desenvolvidas por instituições religiosas). Tratam-se de experiências de educação não formal, "aquela 
que se aprende no mundo da vida", via processos de compartilhamento de experiências, principalmente em espaços e açóes coletivas cotidianas" (GOHN, 2006, p. 28).

Um dos vetores para o funcionamento de redes associativas na comunidade de São Rafael é representado pelo Centro Popular de Cultura e Comunicação, que foi criado pelos moradores da comunidade e, na atualidade, é coordenado por jovens. Dentre suas açóes, destacam-se a rádio, o banco e a padaria comunitários, que buscam a promoção do desenvolvimento do território no que se refere ao campo da economia e da comunicação.

Márcia compartilha desses espaços associativos, inclusive proporcionando formação para outros jovens da comunidade. Para isso, Márcia e esses jovens captam recursos por meio de projetos e são responsáveis pela organização dos cursos, como também os ministram. Esse tipo de prática sugere um forte laço junto à comunidade. Na fala de Márcia, vemos como ela estabeleceu esse vínculo desde cedo.

Eu me apego muito às pessoas, porque eu também não fui criada só com máe e com pai, eu fui criada com os vizinhos da Sáo Rafael [...] É porque é assim, desde o início, então eu não consigo me desvincular disso. Meu projeto de pesquisa foi dentro da padaria, meu artigo agora vai ser dentro da padaria. Vou fazer outra especialização e vai ser com as mulheres da comunidade em relação à doceria. Então, eu não consigo me desvincular disso, sabe?! Eu me envolvo demais. (Márcia).

Essas narrativas se assemelham "aos processos inventivos de experimentação coletiva” a que se refere Takeuti (2012, p. 432):

Jovens de determinados segmentos econômicos inferiores da sociedade "descobriram" na arte um veio de produção de uma nova subjetividade que vem fazer face aos paradoxos que a sociedade lhes impóe. Tratamos, assim, da emergência das minorias sociais juvenis e de suas potencialidades. Entendemos por minoria social aqueles grupos ou coletivos que se orientam para um devir-minoritário, que, por sua vez, é entendido como uma saída das redundâncias dominantes.

Formou-se um grupo de jovens na comunidade que construiu um sentimento de pertencimento a São Rafael - sentimento que está relacionado aos compromissos assumidos junto ao grupo, que se irradia para os demais membros e por toda a comunidade. O sentimento de pertencimento indica a formação de uma rede de convivência e solidariedade que os une em um território onde é possível forjar novas formas do existir (FREITAS, 2005). Talvez, em certa medida, tal rede apresente tentativas de escapar aos processos de normalização e governamento da vida, afirmados pela sociedade de controle. Claro que há manifestações de certo enquadramento nas normas, mas não podemos deixar de considerar tentativas de re(x)istência a certos padróes presentes na sociedade no que diz respeito ao ser jovem nas comunidades. 
Helder é integrante de outra comunidade, na cidade de Zabelê. A exemplo do que acontece na comunidade de São Rafael, por meio do CPCC, em Zabelê existe a Associação Cultural de Zabelê (ASCUZA). Helder diz que a ASCUZA causou grande impacto nos caminhos que ele traçou até o momento. Helder sempre gostou de participar de atividades extraclasses. Paralelamente à sua trajetória escolar, ele conheceu a associação, onde ele diz que teve a possibilidade de mudar de perspectiva diante da vida.

Assim como os jovens da Sáo Rafael falam da rádio comunitária, da (a Amazona e do CPCC), Helder se refere à associação como um lugar de referência na sua formação.

Antes de eu entrar na associação, assim como a grande maioria da população de Zabelê, elas não têm perspectivas de sair de lá não, não tem perspectivas de sonho. Ninguém sonha na verdade. $\mathrm{O}$ maior sonho da população é terminar o ensino médio e ficar lá em Zabelê mesmo. Sem fazer nada, bebendo na praça...essa é a perspectiva das maiorias das populaçóes, principalmente do interior e pobres.

Foi a partir do grupo da ASCUZA que surgiu um coletivo juvenil denominado propositalmente de "Atissar". O coletivo formado por outros jovens de Zabelê constrói estratégias que visam a desenvolver a cultura do município. O grupo criou uma maneira própria de viver juntos. Eles passam Natal, Ano Novo, Carnaval e demais feriados e datas comemorativas juntos. Comunicam-se diariamente, mesmo estando em cidades diferentes. Helder nos relatou que no coletivo aprende todos os dias a importância do cuidado com o outro, o respeito e o compromisso com o grupo. Ele sugere que é no coletivo que se fortalece para atuar em Zabelê. "A gente leva musicalidades que a população não tem acesso mesmo".

Os grupos em que os jovens participantes da pesquisa vão se inserindo parecem ter despertado aprendizagens mobilizadoras neles. Identificamos questóes que estavam ligadas mais ao mundo da vida e das relaçóes afetivas de amizade e de pertencimento ao lugar onde cresceram. Há um processo de formação que fortalece potencialidades individuais e coletivas. Em outras palavras, reconhecemos vivências educativas que são construídas e vividas em coletivos, grupos e redes de solidariedade e que não podem ser explicados ou capturados de maneira concreta. Talvez possa se caracterizar como uma vivência de educação náo formal. Segundo Gohn (2009), a educação não formal pode se complementar ao processo de escolarização, alcançando extensóes culturais e políticas que não cabem em currículos oficiais. Suas práticas podem ocorrer em qualquer idade ou classe socioeconômica. As experiências de educação não formal

se desenvolvem usualmente extramuros escolares, nas organizações sociais, nos movimentos, nos programas de formação sobre direitos humanos, cidadania, práticas identitárias, lutas contra desigualdades e exclusóes sociais (GOHN, 2009, p. 31). 
No que diz respeito às redes de sociabilidade, Gohn (2005) afirma que após os anos 1990 os movimentos populares tomaram novas formas: uma delas é a criação de "redes sociais". Muitas vezes, essas redes são impulsionadas pelas ONGs e por associações, como no caso da comunidade São Rafael e de Zabelê.

Nesse processo de construção das redes, há uma característica que fica evidenciada como sendo primordial para a sua existência: a questão da relação com o outro, que os membros vão construindo em prol da melhoria de vida da coletividade. Talvez as redes estimulem uma vontade criadora, uma vontade de crescimento de expansão de forças e de um movimento que é contrário à permanência e à conservação do que está posto (DIAS, 2011).

\section{Algumas considerações}

Percebemos um engajamento que nos chamou atenção no decorrer das histórias de vida dos jovens entrevistados. Como nos alerta Peruzzo (2002, p. 276): "falar em comunidade significa falar de fortes laços, de reciprocidades, de sentido coletivo dos relacionamentos", sendo um movimento que se forma em torno de identidades variadas, como por exemplo, o local de moradia. Esses entrelaçamentos coletivos e as relaçôes de afetividade com o lugar e seus moradores nos comove nos achados da pesquisa.

Deixa-nos tocadas e, ao mesmo tempo, intrigadas o fato de os jovens terem despertado esse afeto compromissado com o local onde vivem ou viveram. "Eu gosto de trabalhar com o social, eu gosto de trabalhar com o povo. Eu gosto de ajudar, de ficar em cima. Crescer junto! Pelo amor mesmo... eu cresci aqui dentro" (Márcia).

Outro aspecto em comum são as referências que os jovens afirmaram ter tido ao longo de suas trajetórias de vida: professores, pais, educadores dos projetos e, agora, eles se sentem convidados a retribuir as oportunidades que puderam ter. Parece-nos que há um fazer político que exige dedicação, doação e ousadia de arriscar coisas "novas" para suas comunidades e nas suas formas de viver.

Quando olhamos para o modo de viver desses jovens, não nos permitimos aproximá-lo daquelas classificaçóes estigmatizantes utilizadas pelas políticas oficiais, quando se referem à juventude pobre. Há uma recusa àquela maneira de classificação e enquadramento. Por outro lado, não podemos deixar de reconhecer os conflitos e as relaçóes de poder existentes em qualquer agir político. Nas suas narrativas, há oscilações entre agenciamentos e processos de (re)elaboração desses agenciamentos (DELEUZE, 2005).

Observamos movimentos que enquadram os jovens em um percurso de escolarização que é, de certa forma, esperado pela sociedade. De certa forma, porque a trajetória, para eles, seria outra. O comum seria que eles fossem "o jovem do projeto", para, posteriormente, "ser o jovem dos programas governamentais" voltados para a juventude pobre, das periferias; que assumissem subempregos para 
sustentar-se e garantir uma sobrevida. Contudo, as relaçóes de reciprocidade e de afetividade que os jovens estabeleceram com seus territórios os levam a querer uma "vida cada vez mais viva".

Resgatando as ideias de Guattari (1996), lembremos que mesmo que as nossas subjetividades sejam produzidas e fabricadas para seguir modelos hegemônicos e massivos, mesmo que haja máquinas de produção do que devemos ser, do que devemos sonhar e de como devemos nos apaixonar, há uma ideia oposta de que é possível desenvolver modos de subjetivação singulares: aquilo que podemos chamar de processos de singularização - uma maneira de recusar esses modelos predeterminados. Recusá-los para criar novas formas de ser, de viver, de existir.

Assim, acreditamos que os saberes que mobilizam as ações das políticas de juventude (seus referenciais normativos) devem ser (re)pensados. Esses referenciais podem ser (re)formulados, quando mudarmos nosso olhar sobre a realidade da juventude das periferias. Há condições precárias, no sentido material, que acompanham os jovens, mas há também grandes potências de vida, que os mobilizam a viver de maneira diferente das propagadas socialmente. Esperamos que possamos pensar outras formas de fazer política. Talvez "a política da imaginação", como nos sugere Ortega (2009). Uma política do exercício do olhar crítico diante do que vemos, do que somos e do que nos parece tão óbvio. Do exercício de criarmos sempre novas formas de sociabilidade e de relacionamento para, assim, podermos pensar em outras formas de fazer políticas de juventude.

\section{Notas}

1. Em função dos limites de espaço deste texto, elegemos apenas duas histórias de vida para serem analisadas e problematizadas.

2. Como já mencionamos anteriormente, no âmbito deste artigo, trabalharemos com duas histórias de vida consideradas relevantes para o estudo.

3. Para maior aprofundamento, ver Oliveira (2015).

4. A comunidade de São Rafael localiza-se no bairro do Castelo Branco, zona sul da cidade de João Pessoa (PB). Encontra-se entre o Rio Jaguaribe e a BR- 230, nas proximidades da Universidade Federal da Paraíba (UFPB). É uma comunidade relativamente pequena, o que proporciona certa aproximação entre as famílias.

5. Zabelê possui pouco mais de 2 mil habitantes e é localizado na regiâo do Cariri Paraibano, Semi-Árido. Segundo documentos oficiais da Associação Cultural de Zabelê, local onde surgiu o coletivo do qual o jovem faz parte, a população de Zabelê é, na sua maioria, formada por jovens "excluídos da vida econômica e com escolaridade precária".

6. http://portal.mec.gov.br/cotas/index.html.

7. Ver Melo Neto e Oliveira (2015). 


\section{Referências}

AZEVEDO, J.M.L. A educação como política pública. São Paulo: Autores Associados, 2003.

BOURDIEU, Pierre. Questôes de sociologia. Lisboa: Fim de Século Edições, 2003.

BRANCO, G.C. As resistências ao poder em Michel Foucault. Trans/Form/Ação, Marília, v. 24, n. 1, p. 237-248, 2001. Disponível em: <http://www.scielo.br/pdf/trans/v24n1/v24n1a16. pdf $>$. Acesso em: 02 fev. 2015. http://dx.doi.org/10.1590/S0101-31732001000100016

BRASIL. Lei n. 12.852, de 5 de agosto de 2013. Institui o Estatuto da Juventude e dispóe sobre os direitos dos jovens, os princípios e diretrizes das políticas públicas de juventude e o Sistema Nacional de Juventude - SINAJUVE. Diário Oficial da União, Brasília, DF, 6 ago. 2013.

CASTRO, E. Vocabulário de Foucault: um percurso pelos seus temas, conceitos e autores. Tradução Ingrid Müller Xavier. Revisão técnica Alfredo Veiga-Neto e Walter Omar Kohan. Belo Horizonte: Autêntica, 2009. 477 p.

DELEUZE, G. Foucault. São Paulo: Brasiliense, 2005.

DIAS, R. Nietzsche, vida como obra de arte. Rio de Janeiro: Civilização Brasileira, 2011.

FOUCAULT, M. Microfísica do poder. Rio de Janeiro: Graal, 1997.

. Nascimento da biopolítica. São Paulo: Martins Fontes, 2008.

- Vigiar e punir: nascimento da prisão. Tradução Raquel Ramalhete. 40. ed. Petrópolis: Vozes, 2012.

FREITAS, A.S. Fundamentos para uma sociologia crítica da formação humana: um estudo das redes associacionistas da sociedade civil. 2005. Tese (Doutorado) - Centro de Filosofia e Ciências Humanas, Universidade Federal de Pernambuco, Recife, 2005.

O (des)governo da razão: biopolítica e resistência nas políticas públicas de juventude. In: CONGRESSO BRASILEIRO DE SOCIOLOGIA, 14., 2009, Rio de Janeiro. Anais... Rio de Janeiro, Sociedade Brasileira de Sociologia, 2009.

GOHN, M.G.. Educação não-formal, educador(a) social e projetos sociais de inclusão social. Meta: Avaliação, Rio de Janeiro, v. 1, n. 1, p. 28-43, jan./abr. 2009

Educação não-formal, participação da sociedade civil e estruturas colegiadas nas escolas. Ensaio: Avaliação e Políticas Públicas em Educação, Rio de Janeiro, v. 14, n. 50, p. 27-38, jan/mar. 2006. http://dx.doi.org/10.1590/S0104-40362006000100003

O protagonismo da sociedade civil: movimentos sociais, ONGs e redes solidárias. São Paulo: Cortez, 2005.

GROPPO, L.A. Condição juvenil e modelos contemporâneos de análise sociológica das juventudes. Última Década, Valparaíso, Chile, v. 18, n. 33, p. 11-26, dez. 2010.

GUATTARI, F. \& ROLNIK, S. Micropolítica: cartografias do desejo. Petrópolis: Vozes, 1996. JOVCHELOVITCH, S.; BAUER, M. Entrevista narrativa. In: BAUER, M.; GASKELL, G. Pesquisa qualitativa com texto, imagem e som: um manual prático. Petrópolis: Vozes, 2010. 
LAZZARATO, M. Biopolítica/bioeconomia. In: PASSOS, I.C.F. (Org.). Poder, normalização e violência: incursóes foucaultianas para a atualidade. Belo Horizonte: Autêntica, 2008.

MELO NETO, R.D.; OLIVEIRA, M.L. As diferenças entre o dito e o percebido nas políticas de juventude do governo Lula: caso Prouni e Projovem original em Pernambuco. Educação e Cultura Contemporânea, Rio de Janeiro, v. 12, n. 27, p. 212-230, 2015.

OLIVEIRA, M.L. Governamentalidade e inclusão pela gestão dos riscos nas políticas de juventude: um estudo a partir dos egressos do Projovem. 2011. Dissertação (Mestrado em Educação) - Universidade Federal de Pernambuco, Recife, 2011.

. Políticas de juventude, governo da vida e educação: uma aproximação às açóes de re(x)istência de jovens moradores das periferias na Paraíba. 2015. 200f. Tese (Doutorado em Educação) - Universidade Federal de Pernambuco, Recife, 2015.

ORTEGA, F. Para uma política da amizade: Arendt, Derrida, Foucault. Rio de Janeiro: Relume Dumará, 2009.

PELBART, P.P. Vida capital: ensaios de biopolítica. São Paulo: Iluminuras, 2003.

PERUZZO, C.M.K. Comunidades em tempos de redes. In: PERUZZO, C.M.K.; COGO, D.; KAPLÚN, G. (Org.). Comunicación y movimientos populares: ¿cuáles redes?. Porto Alegre: Unisinos, 2002. p. 275-298.PINEAU, G. Las historias de vida como artes formadoras de la existencia. Cuestiones Pedagógicas, Sevilha, n. 19, p. 247-265, 2008/2009.

RICOEUR, Paul. Escritos e conferências I. Em torno da psicanálise. São Paulo: Loyola, 2010.

SPOSITO, M.P. (Coord.). Espaços públicos e tempos juvenis: um estudo de açóes do poder público em cidades de regióes metropolitanas brasileiras. São Paulo: Global, 2007.

SPOSITO, M.P.; CARRANO, P.C.R. Juventude e políticas públicas no Brasil. Revista Brasileira de Educação, Rio de Janeiro, n. 24, p. 16-39, dez. 2003.

TAKEUTI, N.M. Paradoxos societais e juventude contemporânea. Estudos de Psicologia, Natal, v. 17, n. 3, p. 427-434, set./dez./ 2012. http://dx.doi.org/10.1590/S1413-294X2012000300011

TENÓRIO CAVALCANTI, R. Educação, Estado e organizaçôes sociais: um estudo sobre o papel do Observatório de Favelas na formulação e implementação de Políticas Públicas de Juventude na região metropolitana do Recife. 2011. 151f. Dissertação (Mestrado em Educação) - Universidade Federal de Pernambuco, Recife, 2011.

VEIGA NETO, A. e LOPES, M. Inclusão e Governamentalidade. Educ. Soc., Campinas, v. 28, n. 100 , p. $947-963$, out. 2007.

ZALUARA. Gangues, galeras e quadrilhas: globalização, juventude e violência. In: VIANNA, H. (Org.). Galeras cariocas: territórios de conflitos e encontros culturais. Rio de Janeiro: Editora da UFRJ, 1997. 